\title{
A Knowledge Approach for the Library Sciences
}

\author{
Theodore J. Randles, Eastern Kentucky University, USA \\ Sarah Richardson, Eastern Kentucky University, USA \\ Allison Li Miller, Georgia College, USA
}

\begin{abstract}
Like chemistry's table of elements, the knowledge spectrum organizes a large amount of information about knowledge, dividing intelligent behavior into its essential cognitive elements. This paper describes a way to catalog, measure, and analyze organization knowledge requirements and knowledge resources through inheritance of knowledge spectrum properties. Business process knowledge requirements trees and employee knowledge profiles would be created to permit knowledge requirements fulfillment analyses.
\end{abstract}

\section{KEYWORDS}

Knowledge Management, Knowledge Modeling, Knowledge Requirements, Knowledge Spectrum, KnowledgeBased Mapping Systems, Maps of Scientific Exploration, Pragmatic Rules

\section{INTRODUCTION}

An objective of library science is to provide the right information in the right format at the right time (Jain, 2013). This is challenging because librarians often work with many different user groups with diverse needs, and it is difficult for any librarian to remember and quickly point to the best resources for every single need (Ralph \& Ellis, 2009). From a knowledge perspective, the authors suggest that library science determine the pragmatic rules and maps that guide these consultations and use them to enable less expert librarians to act like experts.

The notion of pragmatic rules was borrowed from linguistics with Covington (1998) describing pragmatic rules as - the rules that control what is said when. This notion of pragmatics was extended through a study of one hundred video recordings of diagnostic consultations between medical specialists and physicians/patients in distant rural communities (this is called the practice of distance medicine or telemedicine). With respect to the aforementioned study, a four-stage model was developed that linked behavioral, cognitive, and philosophical (epistemological) aspects of the medical diagnostic process. This model rests on the work of the epistemologist Fred Dretske who stated that behavior was a causal chain governed by three knowledge types - each with a different role. The triggering cause signaled the presence of an external event. The role of the structuring cause was to motivate action by explaining the relationship between a signal and an external event. The third type of knowledge was described as a map, attached to a belief that guides one's actions (Dretske, 1988). 
In writing this paper for library science, it was immediately recognized that a researcher's variables for a literature search marked a place in a vast knowledge space. This insight emerged from an understanding of Dretske, and just by asking selected researchers to list the theories (maps) that guide them in their conduct of the literature search, librarians might be able to identify emerging schools of thought and link diverse groups of researchers.

Randles and Fadlalla (2004) introduced the knowledge chemistry approach. In this paper the authors suggest that library science implement this knowledge chemistry approach. Furthermore, it is suggested that library science adopt the tools that have, or are being developed, to support the knowledge chemistry approach. Through implementation of a set of suggested activities, library scientists would gain a deep understanding of knowledge workers' use of knowledge and would be poised to support and manage them.

\section{LITERATURE REVIEW}

For over twenty years a handful of knowledge management researchers have focused on the notion of pragmatics. How pragmatics and the internal maps that guide knowledge workers gained their attention is discussed next. This discussion serves as a helpful introduction to pragmatics as well as serving as the introduction for the literature review, and these introductory statements begin with a discussion of a study of distance medicine.

Teleconferencing technologies enable medical specialists to confer with distant physicians and patients to conduct medical diagnoses. To study how teleconferencing impacted medical diagnostic practices, a four-stage model of the medical diagnostic process was developed by Randles and Thachenkary (2002). Discovery of Covington's pragmatic rules - rules which control what is said when - focused the attention of the aforementioned researchers on pragmatics, and a study of the semiotic process contributed to their understanding of this topic.

Semiotics describes several levels of transformation: morphological, syntactic, semantic, and pragmatic. Stimuli at the morphological level are merely a collection of unconnected symbols. By relating these symbols to each other, the stimuli are elevated to the syntactic level to produce data. At the semantic level, meaning is attributed to the data to generate information (Ramaprasad and Rai, 1996). Finally, at the pragmatic level, the meaning of information is interpreted in a particular context, and is related to events and action (Stamper, 1973; and Penzias, 1989). A study of distance medicine and the medical diagnostic process revealed the following. Decision making entails a rapid ascent to the pragmatic level of the semiotic process. The physician readily attributes meaning to the medical data. Within minutes the physician has placed the patient's situation in a particular context, reducing the number of potential illnesses from hundreds to five or six.

Based on an increasing awareness of pragmatics, the four-stage model was generalized for knowledge management, using an engine and vehicle analogy to explain the process of information dissipation (Randles and Fadlalla, 2004). According to these researchers, information dissipation is a two stage process. The first stage requires the transformation of information to attain insight (knowledge combustion) with Dretske's three knowledge types linking meaning, events, and action to support an explanation of what occurs at the pragmatic level of the semiotic process.

However, according to the aforementioned researchers, insight is the prelude to action and does not describe what is required to act. Consequently, Randles and Fadlalla (2004) provided a vehicle analogy to describe how cognition moved from insight to action. The physical model analogy of the aforementioned researchers provided a better understanding of the cognitive functions that are performed at the pragmatic level of the semiotic process - a level which had been ignored by information managers (Nonaka, 1994).

Together, the fuel specifications (representing the pragmatic processes) and the force specifications (representing action) provided rudimentary principles regarding the dissipation of information (Randles and Fadlalla, 2004). A reviewer of the aforementioned paper challenged these 
researchers to find ways to apply the aforementioned physical model analogy, and Randles, Blades, and Fadlalla (2008) used knowledge about the hypothesis testing form of knowledge combustion to provide a conceptual design for a novel knowledge based technology. Unfortunately, the video recordings upon which the conceptual design was based were no longer available for analysis. This stymied attempts to develop a prototype system, and the aforementioned researchers focused on the development of tools for the knowledge chemistry approach, instead.

The first tool of the knowledge chemistry approach was the knowledge spectrum. Like the periodic table provides information about the elements, the knowledge spectrum provides information about seven different knowledge types. Furthermore, a dialogue almost naturally emerges from the knowledge spectrum, and it has been shown by Randles and Miller (2020) that this dialogue can support the cataloging of organization knowledge requirements and the conduct of knowledge requirements fulfillment analysis (KRFA). The four-stage model, knowledge spectrum, physical model analogy, hypothesis testing knowledge blend (HTKB) technologies, and other concepts are described in the literature review. However, before their introduction, a brief review of the relationship between knowledge management and library science is provided.

\section{Library Science and Knowledge Management}

The concept of knowledge management $(\mathrm{KM})$ has only recently been explored in higher education and library science. Kidwell, et al. (2000) discussed the application of KM in higher education, such as in curriculum development and strategic planning, and Shanhong (2000) wrote about the increasing importance of KM regarding library innovation, noting that the Internet and digitization were rapidly changing the field. However, despite the emergence of $\mathrm{KM}$ as a topic in the library and information system (LIS) literature, it remains rather unfocused. Perhaps, this is because the concept of KM is far-reaching with many branches. Consequently, it is difficult to locate a single, comprehensive definition of KM. As a result, there is no consensus on how to best utilize KM concepts (Agarwal and Islam, 2014). Although there is agreement that KM brings more roles and opportunities to the LIS profession (Roknuzzaman \& Umemoto, 2013; Koloniari \& Fassoulis, 2017; Sarrafzadeh, Martin, \& Hazeri, 2010).

On the surface, KM and LIS appear to be closely related. As Nazim and Mukherjee (2016) stated, KM has a long history in library practice because librarians have been managing codified or recorded knowledge for a long time. Although librarians have developed multiple classification schemes, including Colon Classification (CC), Library of Congress Classification (LCC), and specialized schemes such as the National Library of Medicine (NLM) classification system, Koenig (2005) noted that KM has ignored LIS's expertise.

LIS professionals have also made contributions in the development and organization of intranet, portals, and websites (Nazim \& Mukherjee, 2016) and have used various KM tools to capture and store knowledge to help with reference services. For example, Stover (2004) wrote about converting tacit knowledge into explicit, codified knowledge through analysis of San Diego State University Library's reference database. Jain (2013) wrote about QuestionPoint which provided a virtual reference service, and Daneshgar and Pariokh (2007) proposed a Customer Knowledge Management (CKM) framework. This framework would help LIS professionals collect information which would be integrated and analyzed to provide information called Knowledge for Customers (Daneshgar \& Pariokh, 2012).

\section{The Four-Stage Model of the Diagnostic Process}

Based on an understanding of diagnostic milestones, forms of insight, and types of knowledge, Randles and Thachenkary (2002) provided a four-stage model of the medical diagnostic process. Each stage relied most prominently on a different knowledge type, attained a different form of insight, and achieved a different diagnostic milestone. The model's foundation was Dretske's definition of knowledge, and problem framing is the first stage of the four-stage model. This stage relies on Dretske's triggering 
cause and attains Sternberg's (1987) selective encoding form of insight. Selective encoding requires the identification of a small amount of relevant data from a large amount of mostly irrelevant data.

In the second stage, the problem formulation stage, a problem space map is generated which is subsumed in the third stage - hypothesis testing. Hypothesis testing is a step-by-step process which corresponds to Sternberg's selective comparison form of insight. This form of insight requires the comparison of information that is current to information acquired in the past. Finally, the fourth stage is confirmation. In this stage other seemingly improbable illnesses are considered and anomalies are explained. Confirmation requires the selective combination form of insight in which the relationship between seemingly unrelated things is determined. Selective combination requires the processing of a vast amount of textbook knowledge which is embedded in the structuring cause (Randles and Thachenkary, 2002).

\section{Knowledge Spectrum}

The knowledge spectrum is based on seven knowledge types, and the six pragmatic knowledge types (declarative knowledge, rules, signals, maps, technical knowledge, and structuring cause) are placed on a continuum according to their explicitness, technical feasibility, and ability to generate cognitive force. Semantic knowledge is internal interacting with the external world through the six pragmatic knowledge types (Randles, Blades, and Fadlalla, 2012).

Drawing from Eysenck and Keane (1990), Randles, Blades, and Fadlalla (2012) defined declarative knowledge as the knowledge of knowing that (such as knowing that a specific diagnostic procedure should be conducted). With respect to rule-based knowledge, numerous examples were provided, such as Weick and Bougon (1986), who stated that predictive and associative knowledge were a collection of rules for processing information, and Covington (1998), who described pragmatic rules as rules of knowing what to say when. Finally, the triggering cause signals the presence of an external event and is like a signal, alarm, or indicator.

Drawing from a number of researchers, Randles, Blades, and Fadlalla (2012) stated that tacit knowledge has a component that is technical, which is the knowledge of how to do something and is also referred to as procedural knowledge (Fetzer and Almeder, 1993). Technical knowledge resides in the mind and the body (Polanyi, 1966), and is placed in the middle of the knowledge spectrum establishing a broad boundary between tacit and explicit knowledge types.

Dretske (1988) stated that the structuring cause, which explains why to act, is the most important knowledge type. According to the knowledge spectrum, the structuring cause is the most tacit knowledge type. It is a deep network of facts with many of its connections hidden deep inside the structure. The role of the structuring cause is to generate an explanation that motivates action. This requires the identification of relevant strings of thought which may seem unrelated on the surface but are connected at a deeper level (Randles, Blades, and Fadlalla, 2012).

\section{The Physical Analogy and HTKB Technologies}

Using descriptions of the cylinder, carburetor, piston, and other engine components, the physical model analogy of Randles and Fadlalla (2004) extended the four-stage model by linking cognition to a solid physical science. The engine and vehicle analogy described a process in which different knowledge types were required to extract value from information. This extraction process generates systematic action, and through these analogies the process of information dissipation was described.

According to the knowledge combustion analogy, the cognitive equivalent of gasoline is a knowledge blend, and Randles and Fadlalla (2004) proposed that Dretske's three knowledge types are used in different proportions to create four knowledge blends. Generalizing the four stage model, the authors stated that four forms of knowledge combustion (framing, formulation, hypothesis testing, and profound explanation) are common to all decision making. Furthermore, each form of knowledge combustion requires a different knowledge blend, and the creation of these knowledge blends required a new approach which was called knowledge chemistry (Randles and Fadlalla, 2004). 
Randles, Blades, and Fadlalla (2008), proposed a process to transform the artifacts of the medical diagnostic process into a valuable knowledge based technology - the hypothesis testing knowledge blend (HTKB). The aforementioned researchers claimed that the hypothesis testing task was information rather than knowledge-intensive. The ability to collect and analyze diagnostic information (the procedural knowledge requirement) was great. However, the aforementioned researchers stated that procedural knowledge was required to combust the hypothesis testing knowledge blend. It was not a component of the knowledge blend. Consequently, the creation of HTKB technologies avoided this stringent knowledge requirement, and the hypothesis testing knowledge blend should be easily implemented (Randles, Blades, and Fadlalla, 2008).

\section{A KNOWLEDGE APPROACH FOR LIBRARY SCIENCE}

A triggering cause signals the occurrence of an external event and is based on a few critical variables. This signal also invokes the appropriate map, and this interaction plays a critical role in controlling intelligent behavior. For librarians, it is a simple task to establish this important relationship between the triggering cause (signal) and the appropriate map. When providing researchers with assistance in conducting their literature searches, just ask them to identify the theory or theories (maps) that are guiding them.

The search variables provided by a researcher mark a place in a vast knowledge space. This knowledge space is like a globe of the earth with different countries representing different sciences. In step 2, pragmatic rules would be developed that would describe the aforementioned sub-spaces through an analysis of researcher profile information. Additionally, adapting suggestions made for the healthcare industry, audio recordings of the consultations conducted by expert librarians would be made and used to create HTKB technologies. Implementing this third step of the prescribed approach would allow library science to be the first to develop and implement HTKB technologies.

In step 4, the maps that guide the actions of knowledge workers would be identified and studied. Furthermore, the knowledge requirements of an organization's knowledge intensive processes would be defined. As previously stated in the literature review, a dialogue emerges from the knowledge spectrum that can support the cataloging of organization knowledge requirements and the conduct of knowledge requirements fulfillment analysis (KRFA). With the implementation of step 4, librarians would move out-of-the library and into the work environments of myriad knowledge workers moving to the forefront of knowledge management.

\section{Step 1}

For many years, knowledge acquisition has been an obstacle for developers of knowledge-based systems. Although video or audio analysis is considered an excellent knowledge acquisition tool, the process of recording the video (or audio) is considered intrusive. As one medical organization discovered through their practice of distance medicine, when providing support the recording of the consultation is not considered intrusive. This is a simple but important idea. The provision of support should be used as an opportunity to collect data (Randles, Miller, and Sayeed, 2017).

Maps play a prominent role in controlling intelligent behavior. For example, the map guiding our early knowledge management research was based on three concepts: Dretske's definition of knowledge, the five diagnostic milestones of the medical problem solving researchers, and Sternberg's three forms of insight. Each of these concepts could be expressed in less than a dozen sentences. However, these small internal maps focused and guided this research leading to the development of the four-stage model of the medical diagnostic process. Subsequently, the four-stage model and several important insights gained from a video analysis of medical diagnostic consultations lead to the knowledge combustion and vehicle analogy. Similar succinct maps guide other researchers, and library science can easily establish an important link between researchers, search variables, and the maps that guide them by just asking researchers to identify their guiding stars - their maps. 


\section{Step 2}

Traditionally, library science has focused on subjects, authors, and sources. The suggested knowledge approach would link subjects, authors, and sources to the maps that guide them. Researchers' search variables identify sub-spaces, which might represent schools of thought. These schools of thought would be further explored, sub-divided, and described through an analysis of researcher profile information as well as an analysis of researchers' choice of suggested sources. The aforementioned step 2 activities would be conducted when librarians provide researchers with search and retrieval support. Librarians would simply ask selected researchers to briefly explain the reason for their selections. Through these short responses, selected researchers would support the development of pragmatic rules that would link schools of thought (and their researchers) to relevant sources.

A model of scientific exploration would be developed. The intensity of the search (how many selected researchers have followed a similar path) could be determined and emerging sub-sciences identified. For example, in 1994 many knowledge management researchers were using Dretske's early 1980s publications concerning knowledge and the flow of information. While finding this work interesting, Dretske's (1988) explanation of behavior proved more insightful (Dretske stated in the foreword of this book that his earlier work on knowledge and the flow of information was deficient and his explanation of behavior was his stronger work). Dretske's explanation of behavior lead this research in a different direction. Whether or not this path, or another, are traversed by other researchers could be determined through this mapping effort. Over time, these maps of scientific exploration would become increasingly more in depth and valuable.

\section{Step 3}

While just words, the explanations provided by an expert during a consultation are the most explicit aspect of the structuring cause. In the appropriate context, these dialogues are valuable, and this realization inspired the conceptualization of HTKB technologies by Randles, Blades, and Fadlalla (2008). For the library science, step 3 would entail the collection of audio recordings of the consultations provided by its most expert and/or specialized librarians. Because librarians do online consultations as well as consulting through chat services and email, these transcripts would also be used to create the aforementioned HTKB technologies. By providing maps and explanations to less expert or less specialized librarians, these technologies would enable them to conduct complex or specialized consultations.

Development of HTKB technologies would require: 1) audio and textual analysis to identify the pragmatic rules that indicate when to say something, 2) audio and textual analysis to develop problem space and sub-state maps of the aforementioned consultations, 3) extraction of librarians' explanations from the audio recordings of selected consultations, and 4) development of knowledge templates for several dozen specialized consultations. A knowledge template would contain about eight small maps, eight concise explanations regarding why the prescribed actions should be performed and about fifty information processing or pragmatic rules. Knowledge templates would be developed for several dozen specialized or complex consultations. Individual library systems would modify these templates to create their own customized maps and explanations enabling each organization to implement their own best practices. A knowledge-based system (KBS) would use the pragmatic rules to provide maps and explanations to less expert librarians in a timely manner and would function like a GPS mapping system. Library science has the requisite skills. Nazim and Mukherjee (2016) noted that LIS professionals have made contributions in the development and organization of intranets and portals, as well as in the organization and curation of websites. Thus, LIS professionals are well-positioned to develop HTKB technologies. 


\section{Step 4}

The internal maps that guide knowledge workers are generally composed of 7 rules and 7 signals (approximately 1 or 2 pages of information), and HTKB technologies are designed to manage these maps. To extend their role further, librarians would move out-of-the library to the work environments of myriad knowledge workers. In this knowledge management role, librarians would closely analyze the activities of knowledge workers, define the knowledge requirements of their tasks, and devise strategies to increase the relevance and speed which library sources are disseminated to knowledge workers.

Randles, Miller, and Blades (2011) stated that the knowledge spectrum provided a framework for defining and assessing organization knowledge requirements and knowledge resources. According to these researchers, just by describing a process as a sequence of stages, a detailed definition of an organization's knowledge requirements could be generated. This detailed process information was obtained through inheritance of knowledge spectrum properties, and their proposed approach would enable business process managers to develop business process knowledge requirements (BPKR) trees.

BPKR trees would support: the definition of knowledge requirements and the creation of employee knowledge profiles. To define these requirements, knowledge spectrum information would be used to establish a dialogue with a firm's business process managers. The resulting requirements would be stored in BPKR trees, and the stored requirements information would be used to establish a dialogue with the firm's knowledge workers. This dialogue would enable employees to create their knowledge profiles, and this profile information would be used to support the conduct of knowledge requirements fulfillment analyses (Randles, Miller, and Blades, 2011).

Moment models depict the interactions that occur in a moment's time (several minutes or less). These interactions are represented as links in a moment model, and these links represent seven components of cognitive force. The first three components: cohesion, coherence, and synergy form a summary measure. The other four components: complement, initiate, promote, and strengthen provide detail and permit a more in-depth description of how cognitive force is generated. The first level of a moment model presents a static view, the second level provides a dynamic view, and the third level supports an analysis of the explanations which are generated by knowledge workers. This level 3 analysis should lead to a better understanding of the structuring cause - a deep and powerful knowledge type that is the root of creativity.

\section{CONCLUSION}

Library scientists will begin to hone their mapping skills through implementation of step 1 and step 2 activities. In step 1, researchers are linked to the maps that guide them. In step 2 pragmatic rules are developed that link schools of thought and researchers to relevant sources. In the near future these pragmatic rules should also link knowledge workers to relevant sources (and maps), and library science will lead the effort to manage the maps that guide knowledge workers.

Through implementation of step 3 and step 4 activities, library science would gain experience in the development of HTKB technologies and a deep knowledge about knowledge workers' use of knowledge. By developing HTKB technologies to support less expert librarians in the conduct of complex or specialized consultations, libraries would be the first organization to reach the advanced mapping level called governance which is described by Randles, Miller, and Sayeed (2017). This would position library science as a leader in knowledge management. Leaders who are prepared to guide myriad knowledge intensive industries to advanced mapping levels. This seems fitting, as librarians were the first knowledge managers.

The components of HTKB technologies: problem space maps, sub-state maps, information processing rules, and pragmatic rules are critical components in the conduct of complex skills. The development of HTKB technologies should serve as a stepping-stone toward the replication of complex 
human skills using computers, allowing library science to take a prominent role in the development of artificial intelligence.

The knowledge approach for library science provides clarity where there is currently no consensus or direction. The establishment of an alliance between library science and the science of knowledge management is suggested. Perhaps, in the near future, the importance of this alliance will become apparent and major universities across the globe will establish colleges of knowledge and library science. 


\section{REFERENCES}

Agarwal, N. K., \& Islam, M. A. (2014). Knowledge management implementation in a library: Mapping tools and technologies to phases of the KM cycle. Vine, 44(3), 322-344. doi:10.1108/VINE-01-2014-0002

Covington, M. A. (1998). Speech acts, electronic commerce, and KQML. Decision Support Systems, 22(3), 203-211. doi:10.1016/S0167-9236(97)00059-6

Daneshgar, F., \& Parirokh, M. (2007). A knowledge schema for organisational learning in academic libraries. Knowledge Management Research and Practice, 5(1), 22-33. doi:10.1057/palgrave.kmrp.8500127

Daneshgar, F., \& Parirokh, M. (2012). An integrated customer knowledge management framework for academic libraries. Library Quarterly: Information, Community Policy, 82(1), 7-28.

Dretske, F. (1988). Explaining behavior. The MIT Press.

Eysenck, M. W., \& Keane, M. T. (1990). Cognitive psychology. LEA.

Fetzer, J. H., \& Almeder, R. F. (1993). Glossary of epistemology/philosophy of science. Paragon.

Jain, P. (2013). Knowledge management in academic libraries and information centres: A case of university libraries. Journal of Information \& Knowledge Management, 12(4), 1350034. doi:10.1142/S0219649213500342

Kidwell, J. J., Vander Linde, K., \& Johnson, S. L. (2000). Applying corporate knowledge management practices in higher education. EDUCAUSE Quarterly, 23(4), 28-33.

Koenig, M. E. (2005). KM moves beyond the organization: The opportunity for librarians. Information Services \& Use, 25(2), 87-93. doi:10.3233/ISU-2005-25203

Koloniari, M., \& Fassoulis, K. (2017). Knowledge management perceptions in academic libraries. Journal of Academic Librarianship, 43(2), 135-142. doi:10.1016/j.acalib.2016.11.006

Nazim, M., \& Mukherjee, B. (2016). Knowledge management in libraries: Concepts, tools and approaches. Chandos Publishing.

Nonaka, I. (1994). A dynamic theory of organizational knowledge creation. Organization Science, 5(1), 14-37. doi:10.1287/orsc.5.1.14

Penzias, A. (1989). Ideas and Information. Simon \& Schuster.

Polanyi, M. (1966). The tacit dimension. Routledge \& Kegan Paul.

Ralph, L. L., \& Ellis, T. J. (2009). An investigation of a knowledge management solution for the improvement of reference services. Journal of Information, Information Technology, and Organizations, 4(1), 17-18. doi: $10.28945 / 124$

Ramaprasad, A., \& Rai, A. (1996). Envisioning management of information. Omega, 24(2), $179-193$. doi:10.1016/0305-0483(95)00061-5

Randles, T., \& Miller, A. (2020). Knowledge Requirements Fulfillment Analysis. (Submitted)

Randles, T., Miller, W., \& Sayeed, L. (2017). The underlying SccoB processes: Knowledge micro analysis, exploratory mapping processes, and action threshold management. American Journal of Management, 17(1), 47-56.

Randles, T., \& Thachenkary, C. (2002). Towards an understanding of diagnostic teleconsultations and their impact on diagnostic confidence. Telemedicine Journal and e-Health, 8(4), 377-383. doi:10.1089/15305620260507512 PMID:12626107

Randles, T. J., Blades, C. D., \& Fadlalla, A. (2008). The hypothesis testing knowledge blend. Knowledge Management Research and Practice, 6(4), 339-349. doi:10.1057/kmrp.2008.20

Randles, T. J., Blades, C. D., \& Fadlalla, A. (2012). The knowledge spectrum. International Journal of Knowledge Management, 8(2), 65-78. doi:10.4018/jkm.2012040104 
Randles, T. J., \& Fadlalla, A. (2004). Knowledge combustion: A knowledge chemistry approach and a description of the process of information dissipation. Journal of Information and Knowledge Management, 3(4), 373-383. doi:10.1142/S0219649204000948

Randles, T. J., Miller, W. J., \& Blades, C. D. (2011) Optimizing the Use of Organization Knowledge: Cataloging, Measuring, and Analyzing Organization Knowledge Requirements and Knowledge Resources. Paper presented at the Annual National Decision Sciences Institute Meeting, Boston, MA.

Roknuzzaman, M., \& Umemoto, K. (2013). Exploring LIS academics' responses to knowledge management. Library Review, 62(4/5), 293-311. doi:10.1108/LR-07-2012-0072

Sarrafzadeh, M., Martin, B., \& Hazeri, A. (2010). Knowledge management and its potential applicability for libraries. Library Management, 31(3), 198-212. doi:10.1108/01435121011027363

Shanhong, T. (2000, August). Knowledge management in libraries in the twenty-first century. Paper presented at the 66th IFLA Council and General Conference, Jerusalem, Israel.

Simon, H. A. (1985). The New Science of Management Decision (3rd ed.). Prentice-Hall.

Stamper, R. (1973). Information. Batsford.

Sternberg, R. J. (1987). Coping with novelty and human intelligence. In P. Morris (Ed.), Modelling Cognition. Wiley.

Stover, M. (2004). Making tacit knowledge explicit: The ready reference database as codified knowledge. RSR. Reference Services Review, 32(2), 164-173. doi:10.1108/00907320410537685

Weick, K. E., \& Bougon, M. G. (1986). Organizations as cognitive maps: Charting ways to success and failure. In H. P. Sims \& D. A. Gioia (Eds.), The thinking organization (pp. 102-135). Jossey-Bass.

Ted Randles (PhD) is an Associate Professor of Computer Information Systems in the College of Business and Technology at Eastern Kentucky University, Richmond, Kentucky. He has a Bachelor's degree in political science from Cleveland State University, Cleveland, Ohio; an MPA from Ohio State University, Columbus, Ohio, and a post undergraduate certificate in information systems from Virginia Commonwealth University, Richmond, Virginia. Dr. Randles earned a Ph.D. in Decision Sciences from Georgia State University, Atlanta, Georgia and has over 15 years of experience as a government and computer systems analyst. His current research interests include knowledge management, intelligent systems, medical information systems, and telemedicine. His research has been published in several journals including the Journal of Information and Knowledge Management, Knowledge Management Research \& Practices, International Journal of Knowledge Management, International Journal of Strategic Decision Sciences, and Telemedicine and E-health Journal.

Sarah Richardson is the Team Leader for Eastern Kentucky University's Business Library and Academic Commons, where she works closely with programs in the College of Business and Technology. She holds a bachelor of science in psychology and religious studies from Radford University and earned her MSLS from the University of Kentucky. Since 2015, she has published in Kentucky Libraries, as well as contributing a chapter to The Complete Guide to Using Google in Libraries.

Allison Li Miller is a Professor of Management at Georgia College. She earned her Ph.D. in Operations Management from the Georgia State University. Her research interests include hospital quality management practices and quality outcomes, teaching Business Analytics, knowledge management, and union industry trends. Since 1996 she has published in a number of journals including the TQM Journal, Quality Progress, the Journal of Quality Management, the International Journal of Strategic Decision Sciences, the Journal of Human Resources in Hospitality and Tourism, and Research in Health Care Financial Management. 